\title{
HGF regulates VEGF expression via the c-Met receptor downstream pathways, PI3K/Akt, MAPK and STAT3, in CT26 murine cells
}

\author{
ATSUSHI MATSUMURA ${ }^{1 *}$, TAKESHI KUBOTA ${ }^{1 *}$, HIROAKI TAIYOH ${ }^{1}$, HITOSHI FUJIWARA $^{1}$, \\ KAZUMA OKAMOTO ${ }^{1}$, DAISUKE ICHIKAWA ${ }^{1}$, ATSUSHI SHIOZAKI ${ }^{1}$, SHUHEI KOMATSU ${ }^{1}$, \\ MASAYOSHI NAKANISHI ${ }^{1}$, YOSHIAKI KURIU ${ }^{1}$, YASUTOSHI MURAYAMA ${ }^{1}$, HISASHI IKOMA ${ }^{1}$, \\ TOSHIYA OCHIAI $^{1}$, YUKIHITO KOKUBA ${ }^{1}$, TAKAHIRO NAKAMURA ${ }^{2}$, \\ KUNIO MATSUMOTO ${ }^{2}$ and EIGO OTSUJI ${ }^{1}$ \\ ${ }^{1}$ Division of Digestive Surgery, Department of Surgery, Kyoto Prefectural University of Medicine, Kamigyo-ku, \\ Kyoto 602-8566; ${ }^{2}$ Division of Tumor Dynamics and Regulation, Kanazawa University \\ Cancer Research Institute, Kakuma-machi, Ishikawa 920-1192, Japan
}

Received September 27, 2012; Accepted November 9, 2012

DOI: $10.3892 /$ ijo. 2012.1728

\begin{abstract}
In the present study, we assessed the involvement of hepatocyte growth factor (HGF)/c-Met signalling with vascular endothelial cell growth factor (VEGF) and hypoxia inducible factor (HIF)-1 $\alpha$ expression in the downstream pathways phosphatidylinositol 3-kinase (PI3K)/Akt, mitogen-activated protein kinase (MAPK) and signal transducer and activator of transcription 3 (STAT3) in CT26 cells, to determine the mechanisms of the potent anti-angiogenic effect of NK4. We established genetically modified CT26 cells to produce NK4 (CT26-NK4). VEGF expression in subcutaneous CT26 tumours in vivo and in culture supernatants in vitro was determined by ELISA. HIF-1 $\alpha$ expression in nuclear extracts was evaluated by western blot analysis. VEGF and HIF-1 $\alpha$ mRNA levels were examined by real-time reverse transcription-polymerase chain reaction (RT-PCR). The DNA binding activity of HIF-1 $\alpha$ was evaluated using an HIF-1 $\alpha$ transcription factor assay kit. Our results demonstrated that VEGF expression was reduced in homografts of CT26-NK4 cells, compared to those of the control cells. In vitro, VEGF expression, which was induced by HGF, was inhibited by anti-HGF antibody, NK4 and by kinase inhibitors (PI3K, LY294002; MAPK, PD98059; and STAT3, Stattic). HGF-induced HIF-1 $\alpha$ transcriptional activity was also inhibited
\end{abstract}

Correspondence to: Dr Takeshi Kubota, Division of Digestive Surgery, Department of Surgery, Kyoto Prefectural University of Medicine, 465 Kajii-cho, Kamigyo-ku, Kyoto 602-8566, Japan

E-mail: tkubot@koto.kpu-m.ac.jp

*Contributed equally

Key words: hepatocyte growth factor, c-Met, NK4, vascular endothelial cell growth factor, angiogenesis, CT26 by the kinase inhibitors. Real-time RT-PCR demonstrated that HGF-induced HIF-1 $\alpha$ mRNA expression was not inhibited by LY294002 and PD98059, but was inhibited by Stattic. These data suggest that the PI3K/Akt, MAPK and STAT3 pathways, downstream of $\mathrm{HGF} / \mathrm{c}-$ Met signalling, are involved in the regulation of VEGF expression in CT26 cells. HGF/c-Met signalling may be a promising target for anti-angiogenic strategies.

\section{Introduction}

Angiogenesis is an essential component of tumour progression and is regulated by a number of hormones, cytokines, growth factors and low molecular mediators (1). One of these molecules, vascular endothelial cell growth factor (VEGF), has a particularly important role. In the solid tumour microenvironment, it is conceivable that focal hypoxia functions as an essential trigger for pathological angiogenesis by the upregulation of VEGF gene expression (2). The principal transcription factor that regulates VEGF expression is hypoxia inducible factor (HIF)-1 $\alpha$, which is stabilised and accumulates under hypoxic conditions as a result of decreased ubiquitination and degradation. HIF-1 $\alpha$ dimerises with HIF-1 $\beta$ and translocates to the nucleus, where they bind to a hypoxia response element (HRE) on the VEGF gene and activate its transcription (3).

On the other hand, hepatocyte growth factor (HGF) is one of the molecules that induces tumour angiogenesis (4). HGF was identified originally as a potent hepatotrophic factor responsible for vigorous regeneration of the liver (5). It is now recognised as a multipotent cytokine that mediates tumour-stromal interaction with mitogenic, motogenic and morphogenic activities $(6,7)$. Moreover, HGF exerts potent angiogenic activity in vascular endothelial cells (8). HGF is a natural ligand for the c-Met proto-oncogene product of receptor tyrosine kinase (7,9). In fact, HGF and c-Met are upregulated in a number of human cancers, such as colorectal, gastric, oesophageal, breast and lung cancers (10-12). The upregulation 
of c-Met inversely correlates with the survival of patients with these types of cancer (13-15).

$\mathrm{HGF} / \mathrm{c}-\mathrm{Met}$ signalling activates multiple signal transduction pathways, including phosphatidylinositol 3-kinase (PI3K)/Akt, mitogen-activated protein kinase (MAPK) and signal transducer and activator of transcription 3 (STAT3) (16-18). The synchronous activation of several signalling pathways is essential for the various biological abilities of HGF (7). In terms of induced angiogenesis, HGF stimulates endothelial cells directly through the c-Met receptor and indirectly by facilitating the expression of other angiogenic factors, represented by VEGF $(19,20)$. In the tumour-stromal interaction, HGF is mainly produced by stromal cells and acts on tumour cells $(21,22)$. Therefore, we hypothesised that stroma-derived HGF induces VEGF expression in tumour cells, resulting in CT26 tumour angiogenesis.

We previously demonstrated that NK4, a competitive antagonist for HGF, potently suppressed murine CT26 tumour growth via inhibiting angiogenesis rather than HGF antagonism (23). NK4 inhibits the angiogenic responses induced by VEGF and basic fibroblast growth factor (bFGF), as well as those of HGF (24). However, the molecular mechanisms by which $\mathrm{HGF} / \mathrm{c}-$ Met signalling regulates VEGF expression in tumour cells in the hypoxic tumour environment are not yet completely understood. To provide further insight into the molecular mechanisms underlying the angiogenic effect induced by the cooperation between HGF and VEGF, we examined the effect of HGF with/without anti-HGF antibody, $\mathrm{NK} 4$, or the inhibitors of kinases downstream of HGF/c-Met signalling, on VEGF and HIF-1 $\alpha$ expression in CT26 cells.

\section{Materials and methods}

Reagents. Recombinant mouse HGF and polyclonal anti-mouse HGF antibody were purchased from R\&D Systems (Minneapolis, MN, USA). Human recombinant NK4 was purified from the conditioned medium of Chinese hamster ovary cells transfected with human NK4 cDNA (25). The PI3K inhibitor, LY294002, and the MAPK inhibitor, PD98059, were purchased from Promega Corp. (Madison, WI, USA). The STAT3 inhibitor, Stattic (a non-peptidic small molecule shown to selectively inhibit the function of the STAT3 $\mathrm{SH} 2$ domain, resulting in the inhibition of STAT3 activation and dimerisation) was obtained from Calbiochem-Merck Co. (Darmstadt, Germany).

Cell lines and culture conditions. CT26 is an undifferentiated colon adenocarcinoma cell line originally derived from intrarectal injections of $\mathrm{N}$-nitroso-N-methylethylamine in a female BALB/c mouse. Cells were maintained in RPMI-1640 (Nacalai Tesque, Inc., Kyoto, Japan) supplemented with 100 IU/ml penicillin, $100 \mu \mathrm{g} / \mathrm{ml}$ streptomycin (Sigma, Welwyn Garden City, UK) and $10 \%$ heat-inactivated fetal bovine serum (FBS; JRH Biosciences, Inc., Lenexa, $\mathrm{KS}, \mathrm{USA})$ at $37^{\circ} \mathrm{C}$ in a humidified atmosphere containing $5 \% \mathrm{CO}_{2}$. Hypoxic condition $\left(1 \% \mathrm{O}_{2}\right.$, $5 \% \mathrm{CO}_{2}, 94 \% \mathrm{~N}_{2}$ ) was achieved using a Wakenyaku $9000 \mathrm{E}$ incubator (Wakenyaku Co., Ltd., Kyoto, Japan).

The genetic modification of CT26 to produce NK4 has been described previously (23). The transfectant expressing the highest amount of NK4 was designated as CT26-NK4. Cells transfected with the neomycin-resistance gene ( $\mathrm{pSVneo}$ ) alone were used as the control (CT26-NEO).
Animal experiments. Female BALB/c mice (8-10 weeks old) were purchased from the Shimizu Laboratory Animal Center

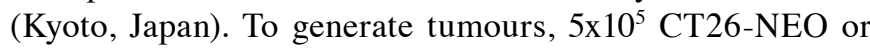
CT26-NK4 cells in $0.1 \mathrm{ml}$ phosphate-buffered saline (PBS) were inoculated subcutaneously into syngeneic BALB/c mice in the right lower flank ( $n=7$ for each group). Considering the difference in tumour growth between CT26-NEO and CT26-NK4, the mice were sacrificed under general anaesthesia when the tumour diameter was $10 \mathrm{~mm}$. After general perfusion of the mice with PBS, tumours were removed and homogenised by a sonic homogeniser. VEGF concentration in the homogenates was quantitatively analysed by ELISA (R\&D Systems). The results were normalised to tumour weight. The animal experiment was approved by the Animal Ethics Committee of the Kyoto Prefectural University of Medicine and was carried out in accordance with the 'Guidelines for the welfare and use of animals in cancer research' (26).

Determination of VEGF expression. The CT26-NEO and CT26-NK4 cells were plated in 24-well culture plates at $1 \times 10^{5}$ cells/well in RPMI with $10 \%$ FBS. After an overnight incubation, the culture medium was replaced and the cells were incubated under serum-starved conditions (RPMI with $0.1 \% \mathrm{BSA}$ ) for $12 \mathrm{~h}$, followed by treatment with $10 \mathrm{ng} / \mathrm{ml}$ mouse recombinant $\mathrm{HGF}$ for $24 \mathrm{~h}$ under normoxic and hypoxic conditions. To examine the effect of $\mathrm{HGF} / \mathrm{c}-M e t$ signalling, $\mathrm{HGF}$ with/without $20 \mathrm{mg} / \mathrm{ml} \mathrm{NK} 4$ or $5 \mathrm{mg} / \mathrm{ml}$ anti-HGF antibody were added. Moreover, to examine the activities of the respective kinase inhibitors, cultured cells were pre-treated with $50 \mathrm{mM}$ PI3K inhibitor (LY294002), $20 \mathrm{mM}$ MAPK inhibitor (PD98059), or $20 \mathrm{mMSTAT} 3$ inhibitor (Stattic) for $60 \mathrm{~min}$ prior to the addition of HGF. The culture supernatants were collected and VEGF concentrations were determined by ELISA.

Quantification of HIF-1 $\alpha$ transcriptional activity. The DNA binding activity of HIF- $1 \alpha$ was evaluated using the HIF-1 $\alpha$ transcription factor assay kit (Cayman Chemical, Ann Arbor, MI, USA) according to the manufacturer's instructions. Cells were plated in 100-mm culture dishes and allowed to grow until subconfluent. Cells were starved for $12 \mathrm{~h}$, pre-treated with the respective kinase inhibitors (50 mM LY294002, $20 \mathrm{mM}$ PD098059 and $20 \mathrm{mM}$ Stattic) and then treated with $10 \mathrm{ng} / \mathrm{ml} \mathrm{HGF}$ under normoxic and hypoxic conditions for $8 \mathrm{~h}$.

Nuclear extracts were prepared and incubated in 96-well plates coated with immobilised double-stranded oligonucleotides containing the HIF-1 $\alpha$ response element (5'-ACGTG-3'). The HIF-1 $\alpha$ transcription factor complex was detected by the addition of a specific primary antibody directed against HIF-1 $\alpha$, visualised by an anti-IgG horseradish peroxidase (HRP)-conjugate and quantified by measuring the absorbance at $450 \mathrm{~nm}$. The DNA binding activity of HIF-1 $\alpha$ was expressed relative to the value of the control (CT26-NEO without HGF treatment under normoxic conditions). The experiments were repeated 2 or 3 times and similar results were obtained.

Western blot analysis. Aliquots of nuclear extracts $(50 \mathrm{mg})$ were fractionated by $7 \%$ sodium dodecyl sulphate (SDS)polyacrylamide gel electrophoresis and transferred onto a polyvinylidene difluoride (PVDF) membrane. The membrane was blocked with 5\% non-fat dried milk in Tris-buffered saline 
containing $0.05 \%$ Tween-20, for $1 \mathrm{~h}$ at room temperature, followed by overnight incubation at $4^{\circ} \mathrm{C}$ with anti-HIF-1 $\alpha$ rabbit polyclonal antibody (NB100-497) (Novus Biologicals, Littleton, CO, USA) at a 1:500 dilution. HRP-conjugated goat anti-rabbit secondary antibody was used at a 1:2,000 dilution. The signal was developed with a chemiluminescence reagent (ECL plus; GE Healthcare, Piscataway, NJ, USA) and the band images were detected with Versa Doc-4000 (Bio-Rad Laboratories, Hercules, CA, USA).

Real-time reverse transcription-polymerase chain reaction $(R T-P C R)$. Subconfluent cells in 100-mm culture dishes were starved for $12 \mathrm{~h}$ and treated with/without $10 \mathrm{ng} / \mathrm{ml}$ mouse recombinant HGF for $6 \mathrm{~h}$ under normoxic and hypoxic conditions. To examine the activities of the respective kinase inhibitors, the cells were pre-treated with $50 \mathrm{mM}$ LY294002, $20 \mathrm{mM}$ PD98059, or $20 \mathrm{mM}$ Stattic for $60 \mathrm{~min}$ before the addition of HGF.

Total RNA was isolated from the cultured cells using an acid guanidinium thiocyanate-phenol (AGTP) solution (Isogen; Nippon Gene, Tokyo, Japan) according to the manufacturer's instructions. The PCR primers used were as follows: VEGF-A, 5'-CTGGATATGTTTGACTGCTGTGGA-3' (sense) and 5'-GTTTCTGGAAGTGAGCCAATGTG-3' (antisense); HIF-1 $\alpha, 5$ '-AGCAGGAATTGGAACATTATTGCAG-3' (sense) and 5'-TGTGGTAATCCACTCTCATCCATTG-3' (antisense). For normalization, the $18 \mathrm{~S}$ ribosomal protein was used as the housekeeping gene: Rps18, 5'-TTCTGGCCAACGGTCTAG ACAAC-3' (sense) and 5'-CCAGTGGTCTTGGTGTGCTGA-3' (antisense). Real-time RT-PCR was then performed using a LightCycler 1.5 (Roche, Basel, Switzerland) and SYBR-Green I (Qiagen, Inc., Valencia, CA). The RT-PCR protocol consisted of a $50^{\circ} \mathrm{C}$ reverse transcription step for $20 \mathrm{~min}$; a $95^{\circ} \mathrm{C} \mathrm{PCR}$ initial activation step for $15 \mathrm{~min}$; followed by 40 cycles of a $94^{\circ} \mathrm{C}$ denaturation for $15 \mathrm{sec}, 60^{\circ} \mathrm{C}$ annealing for $30 \mathrm{sec}$ and $72^{\circ} \mathrm{C}$ extension for $30 \mathrm{sec}$. In order to confirm specific amplification, the PCR products were subjected to melting curve analysis. The results from real-time RT-PCR analysis were normalised to Rps18 and expressed relative to the value of the control (CT26-NEO without HGF treatment under normoxic conditions). Relative expression levels were calculated using the $\Delta \Delta \mathrm{Ct}$ method. Experiments were repeated 2 or 3 times and similar results were obtained.

Statistical analysis. Statistical evaluation was performed with the two-tailed Student's t-test, unless mentioned otherwise in the text. Differences with P-values $<0.05$ were considered statistically significant.

\section{Results}

VEGF expression is reduced in homografts of CT26-NK4. To confirm the hypothesis that the blockade of HGF/c-Met signalling would reduce VEGF expression, resulting in antiangiogenesis, we first compared VEGF expression in vivo between CT26-NEO and CT26-NK4 subcutaneous tumours. CT26 transfectants were inoculated into mice and the VEGF concentrations in the homografts were determined. The VEGF concentration in the CT26-NK4 homografts, relative to the respective tumour weights, was significantly lower than that

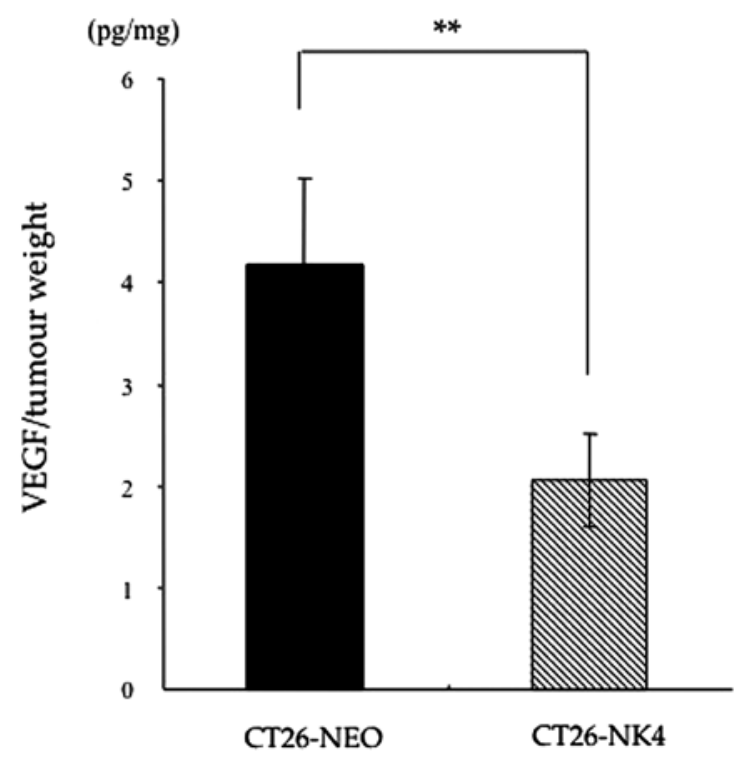

Figure 1. Effect of NK4 gene transfer upon VEGF expression in CT26 homografts. Cells $\left(5 \times 10^{5}\right)$ were inoculated subcutaneously into mice in the right lower flank. Tumours were removed when the tumour major axis was $10 \mathrm{~mm}$. VEGF concentrations in the homogenate of tumours were quantitatively analysed by ELISA. The results were normalised to tumour weight. Bars represent the mean $\pm \mathrm{SD}$. ${ }^{* *} \mathrm{P}<0.01$.

in the CT26-NEO homografts (CT26-NK4 2.1 $\pm 0.5 \mathrm{pg} / \mathrm{mg}$, CT26-NEO 4.2 \pm 0.9 pg/mg; P<0.01) (Fig. 1).

Blockade of $\mathrm{HGF/c-Met} \mathrm{signalling} \mathrm{inhibits} \mathrm{HGF-induced}$ $V E G F$ expression in CT26 cells. We then investigated the effect of HGF on VEGF expression in vitro in CT26-NEO and CT26-NK4 cells under normoxic and hypoxic conditions. In our preliminary experiment, VEGF expression in both transfectants under hypoxic conditions was markedly higher than that under normoxic conditions (data not shown). As regards the effect of HGF, VEGF expression in the transfectants was increased in a HGF-dose-dependent manner. However, VEGF expression in response to $\mathrm{HGF}$ reached a plateau at $10 \mathrm{ng} / \mathrm{ml} \mathrm{HGF}$ in CT26-NEO and at $2.5 \mathrm{ng} / \mathrm{ml} \mathrm{HGF}$ in CT26-NK4 cells.

Under normoxic conditions, in CT26-NEO cells, VEGF expression was 1.6-fold higher under HGF (10 ng/ml) stimulation, but was blocked by the addition of NK4 $(20 \mathrm{mg} / \mathrm{ml})$ or anti-HGF antibody $(5 \mathrm{mg} / \mathrm{ml})$. Under hypoxic conditions, in CT26-NEO cells, the baseline VEGF expression was significantly increased (by 2.4-fold), but a similar block was observed in the presence of HGF with/without NK4 or anti-HGF antibody (Fig. 2a). These results indicate that the alteration in VEGF expression in CT26 cells involves the HGF/c-Met signalling pathway.

In CT26-NK4 cells, the baseline VEGF expression decreased and responded weakly to HGF under normoxic conditions. However, the expression level was lower than that of the control. Under hypoxic conditions, VEGF expression in CT26-NK4 cells significantly increased, but was also lower than that in CT26-NEO cells under hypoxic conditions (Fig. 2b). These results indicate that VEGF expression in CT26 cells is regulated by $\mathrm{HGF} / \mathrm{c}-\mathrm{Met}$ signalling. On the other hand, the exogenous expression of NK4 potently reduced VEGF expression in CT26 cells, even under hypoxic conditions. 


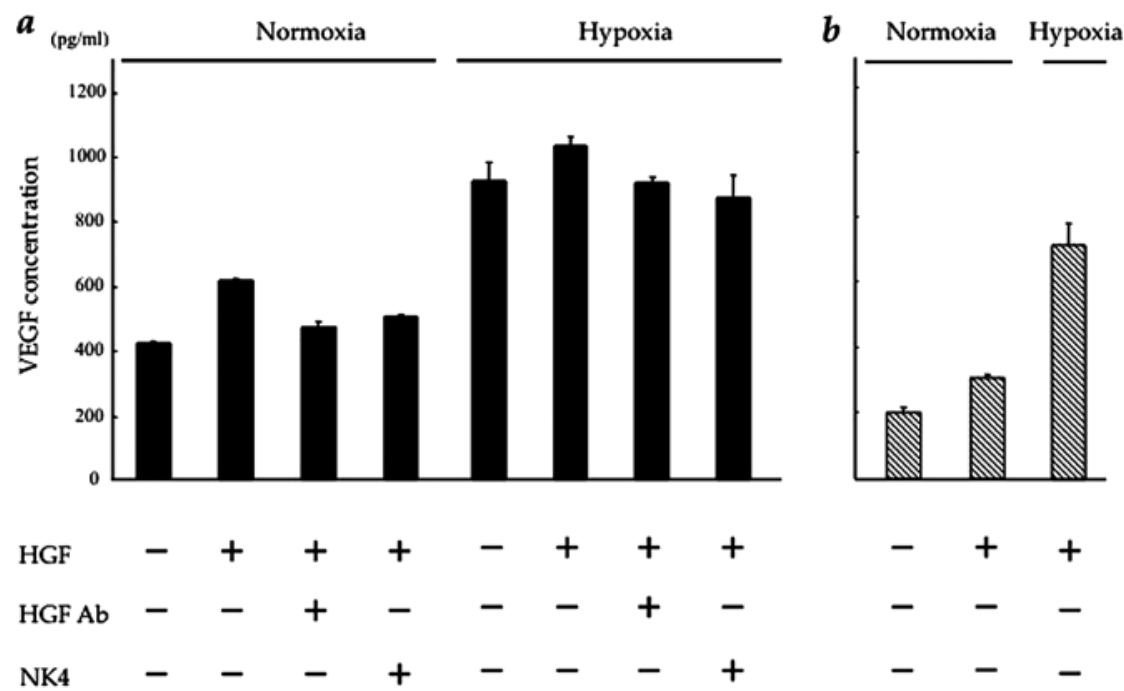

Figure 2. Effect of HGF/c-Met signalling upon VEGF expression in CT26 cells in vitro. Cells were incubated in the presence of $10 \mathrm{ng} / \mathrm{ml} \mathrm{HGF}$ with/without $20 \mathrm{mg} / \mathrm{ml} \mathrm{NK} 4$ or $5 \mathrm{mg} / \mathrm{ml}$ anti-HGF antibody, under normoxic and hypoxic conditions. VEGF concentrations in the culture supernatants were determined by ELISA. (a) CT26-NEO cells, (b) CT26-NK4 cells. Bars represent the mean \pm SD.

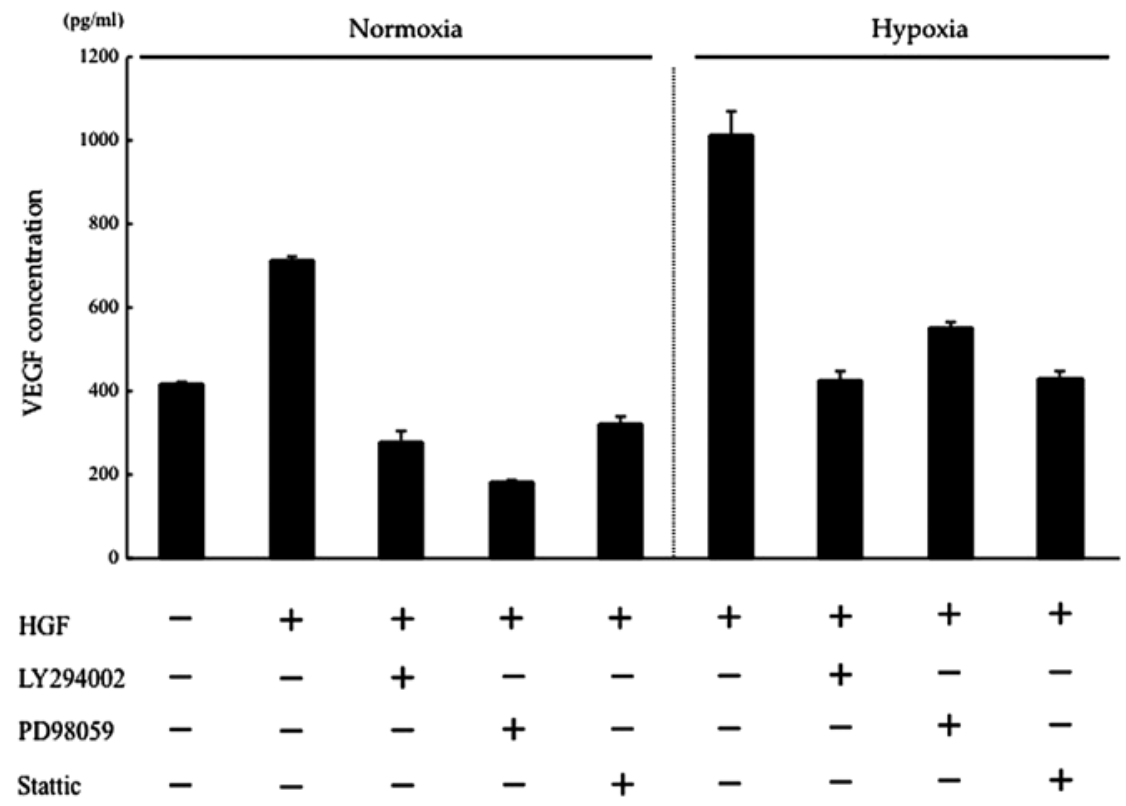

Figure 3. Effect of PI3K/Akt, MAPK and STAT3 signalling on VEGF expression in CT26 cells. Cells were incubated in the presence of $10 \mathrm{ng} / \mathrm{ml} \mathrm{HGF}$ with/without $20 \mathrm{mM}$ MAPK inhibitor (PD98059), $50 \mathrm{mM}$ PI3K inhibitor (LY294002) or $20 \mathrm{mM}$ STAT3 inhibitor (Stattic), under normoxic and hypoxic conditions. VEGF concentrations in the culture supernatants were determined by ELISA. Bars represent the mean \pm SD.

HGF regulates VEGF expression of CT26 cells via the PI3K/Akt, MAPK and STAT3 pathways. HGF/c-Met binding activates several intracellular signalling pathways, including PI3K/Akt, MAPK and STAT3 (4,27). Previously, we showed that the phosphorylation of PI3K, Akt, extracellular-signal-regulated kinase $1 / 2($ ERK1/2) and STAT3 in the CT26 transfectants activated by HGF was inhibited by the addition of anti-HGF antibody or NK4 (28). In this study, we determined which of these pathways may be involved in regulating VEGF expression in CT26 cells, using kinase inhibitors of the PI3K/Akt, MAPK and STAT3 pathways. Under normoxic conditions, HGF-induced VEGF expression was suppressed to a level lower than that of the control by the respective kinase inhibitors. Under hypoxic conditions, VEGF expression, which was increased by HGF, was suppressed to a level almost equal to that of the control by the respective kinase inhibitors. These results suggest that in intracellular HGF/c-Met signalling, the PI3K/Akt, MAPK, STAT3 pathways are involved in the changes in VEGF expression induced by hypoxia (Fig. 3).

$H G F$ regulates $H I F-1 \alpha$ protein synthesis and transcriptional activity in CT26 cells via the PI3K/Akt, MAPK and STAT3 pathways. HIF-1 $\alpha$ is the main transcriptional factor of VEGF under hypoxic conditions (3). Therefore, we investigated the 
$a$

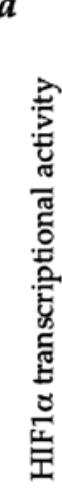

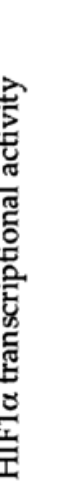

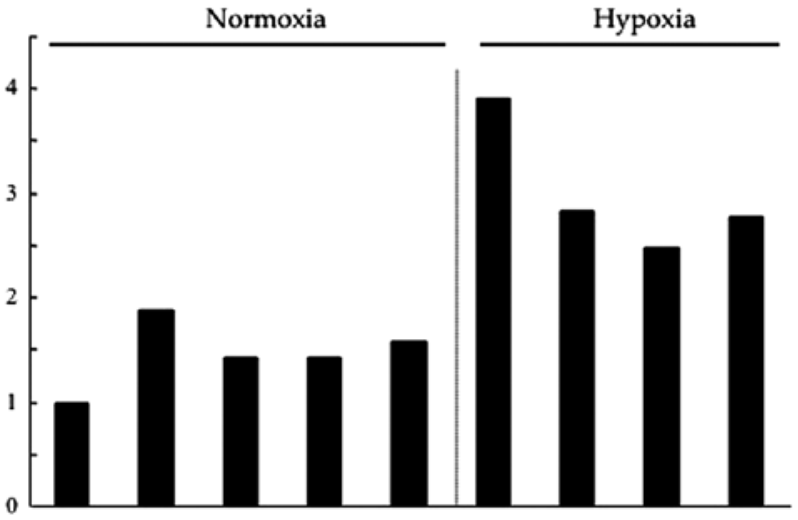

HIFla

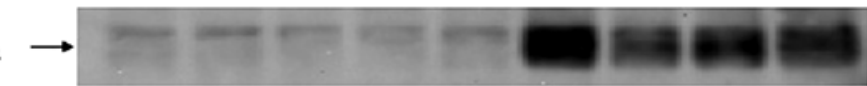

$\begin{array}{llllllllll}\mathrm{HGF} & - & + & + & + & + & + & + & + & + \\ \mathrm{LY} 294002 & - & - & + & - & - & - & + & - & - \\ \mathrm{PD98059} & - & - & - & + & - & - & - & + & - \\ \mathrm{Static} & - & - & - & - & + & - & - & - & +\end{array}$

$b$
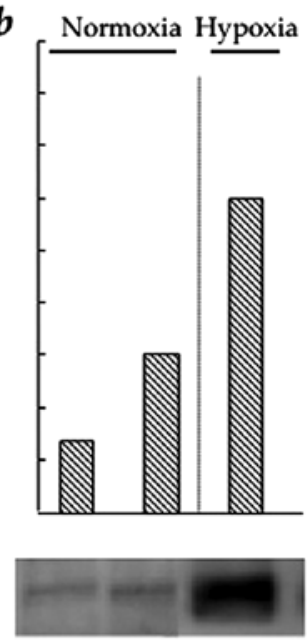

$\begin{array}{lll}- & + & + \\ - & - & - \\ - & - & - \\ - & - & -\end{array}$

Figure 4. Effect of PI3K/Akt, MAPK and STAT3 signalling on HIF-1 $\alpha$ and HIF-1 $\alpha$ transcriptional activity in CT26 cells. Cells were incubated in the presence of $10 \mathrm{ng} / \mathrm{ml} \mathrm{HGF}$ with/without $20 \mathrm{mM}$ MAPK inhibitor (PD98059), $50 \mathrm{mM}$ PI3K inhibitor (LY294002) or $20 \mathrm{mM}$ STAT3 inhibitor (Stattic), under normoxic and hypoxic conditions. HIF-1 $\alpha$ protein expression was analysed by western blot analysis. For HIF-1 $\alpha$ transcriptional activity, the DNA binding activity of HIF-1 $\alpha$ was evaluated using an HIF-1 $\alpha$ transcription factor assay kit. (a) CT26-NEO cells, (b) CT26-NK4 cells .

influence of intracellular HGF/c-Met signalling pathways upon HIF-1 $\alpha$ expression and HIF-1 $\alpha$ transcriptional activity in the CT26 transfectants. In CT26-NEO cells, HIF-1 $\alpha$ expression, which increased slightly in the presence of HGF under normoxic conditions, was stimulated significantly in response to hypoxia. The PI3K, MAPK and STAT3 inhibitors significantly, although incompletely, blocked HIF-1 $\alpha$ expression under hypoxic, as well as normoxic conditions. HIF-1 $\alpha$ transcriptional activity showed a similar trend under normoxic and hypoxic conditions (Fig. 4a). In CT26-NK4 cells, HIF-1 $\alpha$ expression and HIF-1 $\alpha$ transcriptional activity only weakly responded to HGF (Fig. 4b). It was not surprising that HIF-1 $\alpha$ expression and HIF-1 $\alpha$ transcriptional activity were upregulated by hypoxia; however, these results suggest a partial involvement of intracellular $\mathrm{HGF} / \mathrm{c}-$ Met signalling pathways in regulating HIF-1 $\alpha$ expression and HIF-1 $\alpha$ transcriptional activity.

HGF regulates VEGF $m R N A$ in CT26 cells via the PI3K/Akt, $M A P K$ and STAT3 pathways. Based on the result presented in the previous section, we investigated the influence of intracellular HGF/c-Met signalling pathways upon VEGF and HIF-1 $\alpha$ mRNA expression. In CT26-NEO cells, the VEGF mRNA expression level was increased by HGF and, in particular, under hypoxic conditions (by approximately 4-fold) in CT26-NEO cells. HGF induction of VEGF mRNA was prevented by the respective kinase inhibitors (Fig. 5a). The effect of HGF on VEGF mRNA expression in CT26-NK4 cells was minimal. VEGF mRNA expression in CT26-NK4 cells was increased by hypoxia (by approximately 2 -fold), but was lower than that in CT26-NEO cells under hypoxic conditions (Fig. 5b). These results correspond to those obtained for HIF-1 $\alpha$ expression and HIF-1 $\alpha$ transcriptional activity.
$H G F$ regulates $H I F-1 \alpha$ mRNA in CT26 cells via the STAT3 pathway. The HIF-1 $\alpha$ mRNA expression level under hypoxic conditions was equal to or less than the control CT26-NEO cells. Of note, HGF induction of HIF-1 $\alpha$ mRNA was not inhibited by LY294002 or PD98059, but only by Stattic (Fig. 5c). HGF consistently had no effect on CT26-NK4 cells and the effect of hypoxia was similar to that observed in CT26-NEO cells (Fig. 5d). Taken together, the results of real-time PCR and the quantification of HIF-1 $\alpha$ transcriptional activity demonstrated that the PI3K/Akt and MAPK pathways regulate HIF-1 $\alpha$ translation, whereas the STAT3 pathway regulates HIF-1 $\alpha$ mRNA expression.

\section{Discussion}

In the present study, we demonstrate that the HGF/c-Met signalling pathway regulates VEGF expression in CT26 tumour cells. VEGF, which is produced by various cancer cells, acts on endothelial cells and promotes tumour growth and angiogenesis (29). Given that CT26 cells strongly express VEGF, it is hypothesised that VEGF participates in CT26 angiogenesis and subsequent tumour progression. We previously revealed that the production of tumour microvessels in CT26 tumours was significantly inhibited by NK4 gene transfer (23). NK4 is a potent angiogenic inhibitor and its action is independent of HGF antagonism. In in vivo tumours in particular, HGF seems to be the predominant mechanism of angiogenesis (30,31). Kuba et al (24) reported that NK4 exerted a potent anti-angiogenic effect, not only by the blockade of HGF/c-Met signalling, but also by the interruption of intracellular signalling of other growth factors, such as VEGF or bFGF. However, the mechanism we propose in this study is distinct from that previously reported. 
$a$
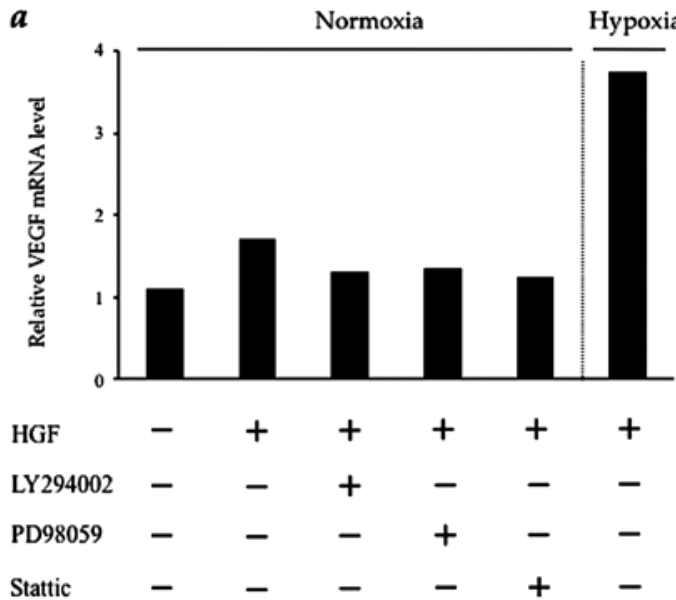

c

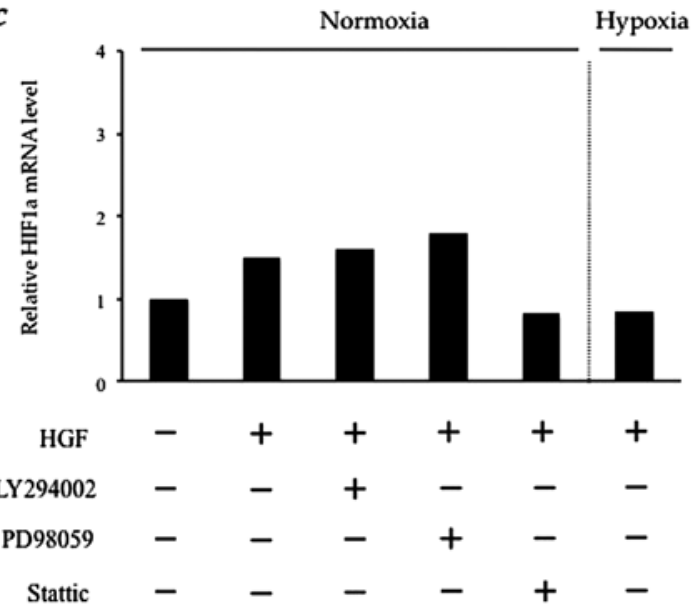

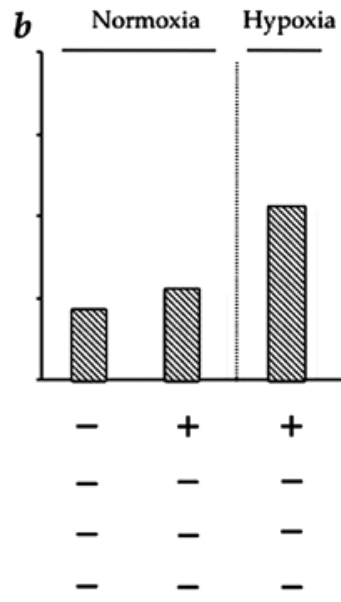

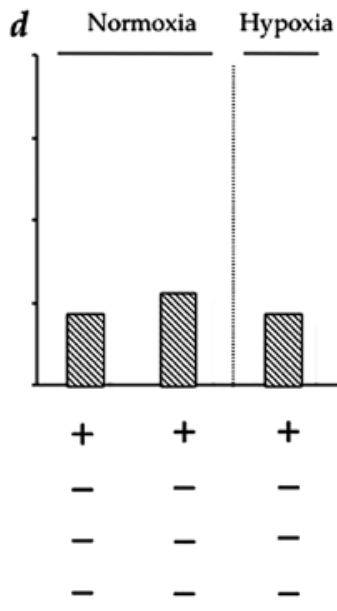

Figure 5. Effect of PI3K/Akt, MAPK and STAT3 signalling on VEGF and HIF-1 $\alpha$ mRNA in CT26 cells. Cells were incubated in the presence of $10 \mathrm{ng} / \mathrm{ml}$ HGF with/without $20 \mathrm{mM}$ MAPK inhibitor (PD98059), $50 \mathrm{mM}$ PI3K inhibitor (LY294002) or $20 \mathrm{mM}$ STAT3 inhibitor (Stattic), under normoxic and hypoxic conditions. VEGF and HIF-1 $\alpha$ mRNA were analysed by real-time RT-PCR. The results are expressed relative to the control value. (a and c) CT26-NEO cells, (b and d) CT26-NK4 cells.

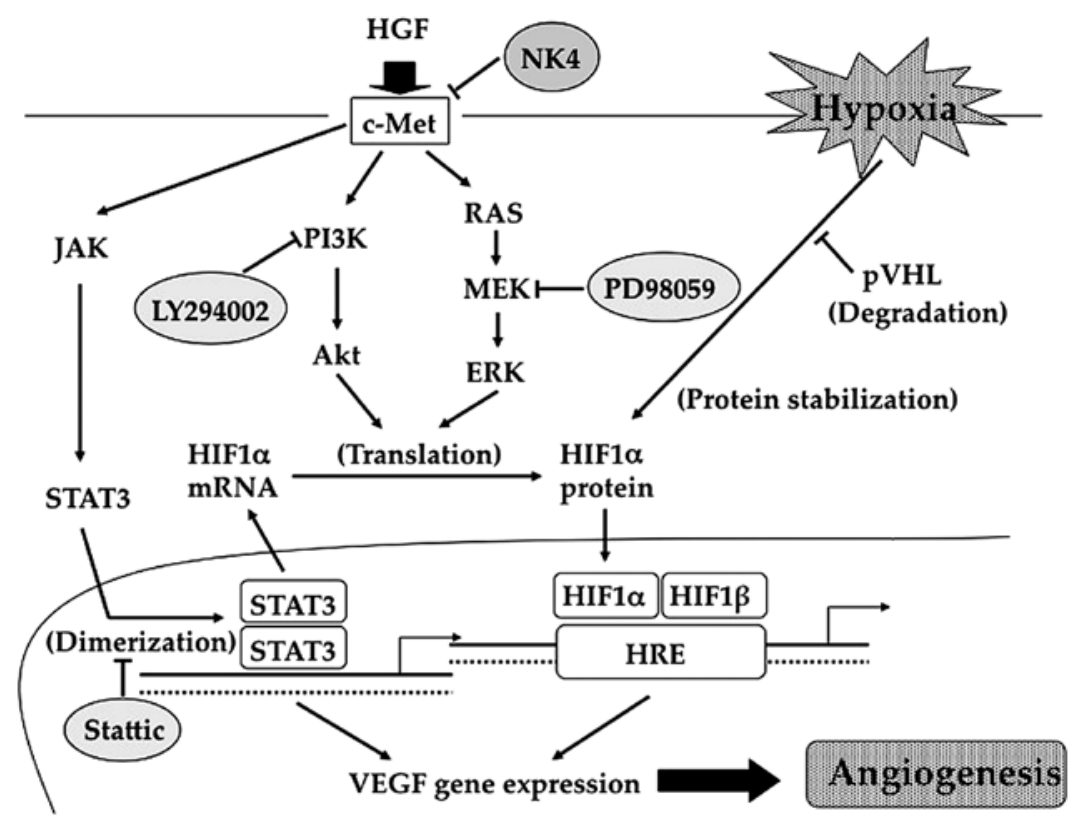

Figure 6. Schematic representation of the interaction of the analysed molecules. HGF binding to its receptor tyrosine kinase, c-Met, activates the phosphatidylinositol 3-kinase (PI3K) and mitogen-activated protein kinase (MAPK) pathways. The activation of PI3K and MAPK signalling translates HIF-1 $\alpha$ mRNA into protein (HIF-1 $\alpha$ synthesis). HIF-1 $\alpha$ binds to HIF-1 $\beta$ in the nucleus and the formed complex activates the VEGF gene. On the other hand, the signal transducer and activator of transcription 3 (STAT3) pathway activates the VEGF gene, not only via direct transcriptional activation, but also via HIF1 $\alpha$ synthesis. HRE, hypoxia response element; pVHL, product of von Hippel-Lindau. 
In our study, we focused on the alteration of VEGF expression in CT26-NK4 tumours. It has now become apparent that no single factor alone can induce structural and functional neovascularisation. HGF stimulates VEGF production in non-endothelial cells $(32,33)$ and increases the expression of VEGF receptors and c-Met in endothelial cells (19). Sulpice et al (34) reported that cross-talk between VEGF and HGF signalling pathways promoted neovascularisation by enhancing intracellular signalling in endothelial cells. Therefore, we hypothesised that NK4 may contribute to the inhibition of tumour growth by decreasing VEGF expression through the $\mathrm{HGF} / \mathrm{c}-\mathrm{Met}$ signalling pathway. Our hypothesis was then proven by the fact that VEGF expression in CT26-NK4 homografts was reduced as compared to the control homografts. In addition, this result was supported by the in vitro experiment under normoxic and hypoxic conditions.

The effect of hypoxia on malignant progression is mediated by a series of hypoxia-induced proteomic and genomic changes, activating angiogenesis, anaerobic metabolism and other processes that enable tumour cells to survive or escape their oxygen-deficient environment (35). The transcription factor, HIF- $1 \alpha$, is a major regulator of tumour cell adaptation to hypoxic stress. Therefore, we assessed which intracellular signalling pathway may be involved in VEGF expression under hypoxic conditions, using the PI3K inhibitor, LY294002, the MAPK inhibitor, PD98059 and the STAT3 inhibitor, Stattic. Our data revealed that the respective kinase inhibitors suppressed the HGF induction of HIF-1 $\alpha$, subsequent HIF-1 $\alpha$ transcriptional activity, VEGF mRNA expression, and VEGF expression, even under hypoxic conditions, indicating that HGF induces HIF-1 $\alpha$ expression and subsequent processes to promote the expression of VEGF via PI3K, MAPK and STAT3 activation (Fig. 6). However, our results demonstrated that the mechanisms involved are more complex. In this study, the HGF induction of HIF-1 $\alpha$ mRNA was not inhibited by the PI3K and MAPK inhibitors, but only by the STAT3 inhibitor. Certain studies have reported that growth factors induce HIF-1-mediated VEGF expression, which is dependent on the MAPK and PI3K pathways $(36,37)$. Therefore, the PI3K/Akt and MAPK pathways regulate VEGF expression via HIF-1 $\alpha$ translation. On the other hand, the ability of STAT3 to activate the VEGF gene as a direct transcriptional activator has previously been demonstrated $(38,39)$. A recent study reported that STAT3 signalling also enhanced the transcriptional activation of the HIF-1 $\alpha$ promoter and contributed to the upregulation of HIF-1 $\alpha$ mRNA (40). Our findings are consistent with these reports. Accordingly, we hypothesised, as shown in Fig. 6, that STAT3 is required not only for the direct activation of the VEGF promoter, but also for HIF-1 $\alpha$-mediated VEGF expression. Therefore, the increase in HIF-1 $\alpha$ mRNA expression induced by HGF was due to STAT3 activation. STAT3 has been reported to influence HIF-1 $\alpha$ protein stability under hypoxic conditions (41), in addition to HIF-1 $\alpha$ protein synthesis induced by oncogenic growth signalling (42). Such phenomena are also evident in our results. Taken together, these data indicate that $\mathrm{HGF} / \mathrm{c}-\mathrm{Met}$ signalling promotes VEGF expression by a complex mechanism involving the PI3K/Akt, MAPK and STAT3 pathways (Fig. 6). Conversely, NK4 suppresses VEGF expression in CT26 tumour cells by inhibiting the activation of intracellular signalling pathways downstream of HGF/c-Met.
In conclusion, the present study provides new and important information concerning the mechanisms by which NK4 exerts its anti-angiogenic effects. These mechanisms partly involve the suppression of VEGF expression in CT26 tumour cells by blocking the activation of the HGF/c-Met signalling pathway. Furthermore, a detailed analysis of the involvement of intracellular HGF/c-Met signalling in VEGF expression showed that the PI3K/Akt and MAPK pathways regulated HIF-1 $\alpha$ translational activity, whereas the STAT3 pathway regulated HIF-1 $\alpha$ transcriptional activity and directly affected VEGF transcriptional activity. These data therefore suggest that $\mathrm{HGF} / \mathrm{c}-\mathrm{Met}$ signalling may be a promising target for the future development of anti-angiogenic strategies to improve response rate and survival in cancer patients.

\section{References}

1. Carmeliet P and Jain RK: Angiogenesis in cancer and other diseases. Nature 407: 249-257, 2000

2. Shweiki D, Itin A, Soffer D and Keshet E: Vascular endothelial growth factor induced by hypoxia may mediate hypoxia-initiated angiogenesis. Nature 359: 843-845, 1992.

3. Liao D and Johnson RS: Hypoxia: a key regulator of angiogenesis in cancer. Cancer Metastasis Rev 26: 281-290, 2007.

4. Trusolino L and Comoglio PM: Scatter-factor and semaphorin receptors: cell signalling for invasive growth. Nat Rev Cancer 2: 289-300, 2002

5. Nakamura T, Nishizawa T, Hagiya M, et al: Molecular cloning and expression of human hepatocyte growth factor. Nature 342 : 440-443, 1989.

6. Jiang WG and Hiscox S: Hepatocyte growth factor/scatter factor, a cytokine playing multiple and converse roles. Histol Histopathol 12: 537-555, 1997.

7. Matsumoto $\mathrm{K}$ and Nakamura T: Emerging multipotent aspects of hepatocyte growth factor. J Biochem 119: 591-600, 1996.

8. Bussolino F, Di Renzo MF, Ziche M, et al: Hepatocyte growth factor is a potent angiogenic factor which stimulates endothelial cell motility and growth. J Cell Biol 119: 629-641, 1992.

9. Bottaro DP, Rubin JS, Faletto DL, et al: Identification of the hepatocyte growth factor receptor as the c-met proto-oncogene product. Science 251: 802-804, 1991.

10. Birchmeier C, Birchmeier W, Gherardi E and Vande Woude GF: Met, metastasis, motility and more. Nat Rev Mol Cell Biol 4: 915-925, 2003.

11. Comoglio PM, Giordano S and Trusolino L: Drug development of MET inhibitors: targeting oncogene addiction and expedience. Nat Rev Drug Discov 7: 504-516, 2008.

12. Maulik G, Shrikhande A, Kijima T, Ma PC, Morrison PT and Salgia R: Role of the hepatocyte growth factor receptor, c-Met, in oncogenesis and potential for therapeutic inhibition. Cytokine Growth Factor Rev 13: 41-59, 2002.

13. Di Renzo MF, Olivero M, Giacomini A, et al: Overexpression and amplification of the met/HGF receptor gene during the progression of colorectal cancer. Clin Cancer Res 1: 147-154, 1995.

14. Ghoussoub RA, Dillon DA, D'Aquila T, Rimm EB, Fearon ER and Rimm DL: Expression of c-met is a strong independent prognostic factor in breast carcinoma. Cancer 82: 1513-1520, 1998.

15. Miller CT, Lin L, Casper AM, et al: Genomic amplification of MET with boundaries within fragile site FRA7G and upregulation of MET pathways in esophageal adenocarcinoma. Oncogene 25: 409-418, 2006.

16. Ponzetto C, Bardelli A, Maina F, et al: A novel recognition motif for phosphatidylinositol 3-kinase binding mediates its association with the hepatocyte growth factor/scatter factor receptor. Mol Cell Biol 13: 4600-4608, 1993.

17. Xiao GH, Jeffers M, Bellacosa A, et al: Anti-apoptotic signaling by hepatocyte growth factor/Met via the phosphatidylinositol 3-kinase/Akt and mitogen-activated protein kinase pathways. Proc Natl Acad Sci USA 98: 247-252, 2001.

18. Boccaccio C, Andò M, Tamagnone L, et al: Induction of epithelial tubules by growth factor HGF depends on the STAT pathway. Nature 391: 285-288, 1998. 
19. Gerritsen ME, Tomlinson JE, Zlot C, Ziman M and Hwang S: Using gene expression profiling to identify the molecular basis of the synergistic actions of hepatocyte growth factor and vascular endothelial growth factor in human endothelial cells. Br J Pharmacol 140: 595-610, 2003.

20. Dong G, Chen Z, Li ZY, Yeh NT, Bancroft CC and Van Waes C: Hepatocyte growth factor/scatter factor-induced activation of MEK and PI3K signal pathways contributes to expression of proangiogenic cytokines interleukin-8 and vascular endothelial growth factor in head and neck squamous cell carcinoma. Cancer Res 61: 5911-5918, 2001.

21. Rosen EM, Goldberg ID, Kacinski BM, Buckholz T and Vinter DW: Smooth muscle releases an epithelial cell scatter factor which binds to heparin. In Vitro Cell Dev Biol 25: 163-173, 1989.

22. Stoker M, Gherardi E, Perryman M and Gray J: Scatter factor is a fibroblast-derived modulator of epithelial cell mobility. Nature 327: 239-242, 1987.

23. Kubota T, Fujiwara H, Amaike H, et al: Reduced HGF expression in subcutaneous CT26 tumor genetically modified to secrete NK4 and its possible relation with antitumor effects. Cancer Sci 95: 321-327, 2004.

24. Kuba K, Matsumoto K, Date K, Shimura H, Tanaka M and Nakamura T: HGF/NK4, a four-kringle antagonist of hepatocyte growth factor, is an angiogenesis inhibitor that suppresses tumor growth and metastasis in mice. Cancer Res 60: 67376743, 2000.

25. Date K, Matsumoto K, Shimura H, Tanaka M and Nakamura T: $\mathrm{HGF} / \mathrm{NK} 4$ is a specific antagonist for pleiotrophic actions of hepatocyte growth factor. FEBS Lett 420: 1-6, 1997.

26. Workman P, Aboagye EO, Balkwill F, et al: Committee of the National Cancer Research Institute: Guidelines for the welfare and use of animals in cancer research. Br J Cancer 102 $1555-1577,2010$.

27. Furge KA, Zhang YW and Vande Woude GF: Met receptor tyrosine kinase: enhanced signaling through adapter proteins. Oncogene 19: 5582-5589, 2000.

28. Kubota T, Taiyoh H, Matsumura A, et al: NK4, an HGF antagonist, prevents hematogenous pulmonary metastasis by inhibiting adhesion of CT26 cells to endothelial cells. Clin Exp Metastasis 26: 447-456, 2009.

29. Brown LF, Berse B, Jackman RW, et al: Expression of vascular permeability factor (vascular endothelial growth factor) and its receptors in adenocarcinomas of the gastrointestinal tract. Cancer Res 53: 4727-4735, 1993.

30. Tomioka D, Maehara N, Kuba K, et al: Inhibition of growth, invasion, and metastasis of human pancreatic carcinoma cells by NK4 in an orthotopic mouse model. Cancer Res 61: 7518-7524, 2001 .
31. Saimura M, Nagai E, Mizumoto K, et al: Tumor suppression through angiogenesis inhibition by SUIT-2 pancreatic cancer cells genetically engineered to secrete NK4. Clin Cancer Res 8: 3243-3249, 2002

32. Van Belle E, Witzenbichler B, Chen D, et al: Potentiated angiogenic effect of scatter factor/hepatocyte growth factor via induction of vascular endothelial growth factor: the case for paracrine amplification of angiogenesis. Circulation 97: 381-390, 1998.

33. Xin X, Yang S, Ingle G, et al: Hepatocyte growth factor enhances vascular endothelial growth factor-induced angiogenesis in vitro and in vivo. Am J Pathol 158: 1111-1120, 2001.

34. Sulpice E, Ding S, Muscatelli-Groux B, et al: Cross-talk between the VEGF-A and HGF signalling pathways in endothelial cells. Biol Cell 101: 525-539, 2009.

35. Vaupel P: The role of hypoxia-induced factors in tumor progression. Oncologist 9 (Suppl 5): 10-17, 2004.

36. Fukuda R, Hirota K, Fan F, Jung YD, Ellis LM and Semenza GL: Insulin-like growth factor 1 induces hypoxia-inducible factor 1-mediated vascular endothelial growth factor expression, which is dependent on MAP kinase and phosphatidylinositol 3-kinase signaling in colon cancer cells. J Biol Chem 277: 38205-38211, 2002.

37. Burroughs KD, Oh J, Barrett JC and DiAugustine RP: Phosphatidylinositol 3-kinase and mek $1 / 2$ are necessary for insulin-like growth factor-I-induced vascular endothelial growth factor synthesis in prostate epithelial cells: a role for hypoxia-inducible factor-1? Mol Cancer Res 1: 312-322, 2003.

38. Niu G, Wright KL, Huang M, et al: Constitutive Stat 3 activity up-regulates VEGF expression and tumor angiogenesis. Oncogene 21: 2000-2008, 2002.

39. Wei LH, Kuo ML, Chen CA, et al: Interleukin-6 promotes cervical tumor growth by VEGF-dependent angiogenesis via a STAT3 pathway. Oncogene 22: 1517-1527, 2003.

40. Niu G, Briggs J, Deng J, et al: Signal transducer and activator of transcription 3 is require for hypoxia-inducible factor-1alpha RNA expression in both tumor cells and tumor-associated myeloid cells. Mol Cancer Res 6: 1099-1105, 2008.

41. Jung JE, Kim HS, Lee CS, et al: STAT3 inhibits the degradation of HIF-1alpha by pVHL-mediated ubiquitination. Exp Mol Med 40: 479-485, 2008.

42. Xu Q, Briggs J, Park S, et al: Targeting Stat3 blocks both HIF-1 and VEGF expression induced by multiple oncogenic growth signaling pathways. Oncogene 24: 5552-5560, 2005. 